\title{
A New Pentacyclic Triterpene from Humata tyermanni Moore with the Inhibitory Activities against LPS-Induced NO Production in RAW264.7 Macrophages
}

\author{
Lei Zhang,, Feng Wang, ${ }^{2}$ Zhen-You Jiang, ${ }^{3}$ Yao-Kui Zhu, ${ }^{1}$ and Ying-Zhou Cen ${ }^{1}$ \\ ${ }^{1}$ Department of Chemistry, Jinan University, Guangzhou 510632, China \\ ${ }^{2}$ Shenzhen Guangming New District Environmental Monitoring Station, Shenzhen Guangming City Construction Bureau, Shenzhen \\ 518107, China \\ ${ }^{3}$ Department of Microbiology and Immunology, School of Medicine, Jinan University, Guangzhou 510632, China
}

Correspondence should be addressed to Ying-Zhou Cen; ofx@jnu.edu.cn

Received 8 April 2012; Accepted 23 May 2012

Academic Editor: Mohammad El-Shahawi

Copyright $\odot 2013$ Lei Zhang et al. This is an open access article distributed under the Creative Commons Attribution License, which permits unrestricted use, distribution, and reproduction in any medium, provided the original work is properly cited.

\begin{abstract}
One new pentacyclic triterpene, hopane-22 (29)-en-24ol (2), with five known hopane-type pentacyclic triterpene compounds: hop-22(29)-ene (1), adiantone (3), 22-hydroxyhopane (4), 6 $\alpha$, 22-dihydroxyhopane (5), and 17(21)-hopene (6) were isolated from Humata tyermanni Moore. The structure of compound 2 was elucidated on the basis of its 1D and 2D NMR spectral analysis. All these compounds were evaluated for their inhibitory activities of LPS-induced nitric oxide (NO) production in RAW264.7 macrophages.
\end{abstract}

\section{Introduction}

Humata tyermanni Moore, a plant belonging to the family of Davalliaceae, is widely distributed in the south part of China $[1,2]$. People of Yao minority usually use it (Bai Mao She) as their traditional herbal medicines, to cure rheumatism, injuries from falls, pulmonary abscess, and so on. In this paper, we described the isolation and structure elucidation of one new pentacyclic triterpene, hopane-22(29)-en-24ol. Its structure was elucidated on the basis of 1D and 2D NMR spectral techniques. In addition, the inhibitory activities of this new compound, together with other five known pentacyclic triterpenes against LPS-induced NO production in RAW264.7 macrophages, were also repotred.

\section{Experimental}

\subsection{Plant Materials}

The dry stems of $H$. tyermanni were bought from traditional Chinese medicine market in Qingping of Guangzhou, in March, 2010. The plant materials were authenticated by
Cai Yuewen pharmacist of traditional Chinese medicine, Guangdong Food, and Drug Vocational College. The voucher specimen (no. 2009ZL1) was deposited in the Laboratory of Natural Products Chemistry, Jinan University, Guangdong province.

2.2. Extraction and Isolation. The dry stems of $H$. tyermanni $(20 \mathrm{~kg}$ ) were extracted with $95 \% \mathrm{EtOH}$ at room temperature for three times. The extract was partitioned between $\mathrm{H}_{2} \mathrm{O}$ and petroleum ether, ethyl acetate in turn. The petroleum ether extract (124 g) was separated through silica gel (200-300 mesh) column chromatography (CC), eluted with petroleum ether/acetone gradient system to yield 17 fractions (from Fr.1 to Fr.17). Recrystallization of Fr.1 yielded compound $\mathbf{1}(150 \mathrm{mg})$. Fr.4 was purified with silica gel CC (petroleum ether : ethyl acetate $=25: 1$ ) and yielded compound $3(28 \mathrm{mg})$ and 6 (65 mg). Fr5 was further purified with silica gel CC (petroleum ether : ethyl acetate $=19: 1$ ) and recrystallized to give compound 2 (31 mg). Fr8 was further purified with silica gel CC (petroleum ether: ethyl acetate $=25: 1$ ) and recrystallized to give compound 5 (22 mg). 
The ethyl acetate extract was separated through silica gel CC (200-300 mesh), eluted with petroleum ether/acetone gradient system and yielded 10 fractions. Fr.5 was purified with silica gel CC and recrystallized (petroleum ether : ethyl acetate $=15: 1)$ to yield compound $4(13 \mathrm{mg})$.

2.3. In Vitro Anti-Inflammatory Assays and Cytotoxicity Testing. These experiments were carried out as previously described [3, 4]. Briefly, RAW264.7 cells grown on $25 \mathrm{~cm}^{2}$ culture flasks were harvested and seeded in 96-well plates at $2 \times 10^{5}$ cells/well for NO production. The plates were pretreated with various concentrations of samples for $30 \mathrm{~min}$ and then incubated for $24 \mathrm{~h}$ with or without $50 \mu \mathrm{g} / \mathrm{mL}$ of LPS. The nitrite concentration in the culture supernatant was measured by the Griess reaction. Cell viability was measured by an MTT [3-(4,5-dimethylthiazol-2-yl)-2,5-diphenyltetrazolium bromide] assay (Sigma-Aldrich).

\section{Results and Discussion}

\subsection{Identification and Structure Elucidation of Compound 2}

Compound 2 was obtained as colorless acicular crystal $\left(\mathrm{CHCl}_{3}-\mathrm{MeOH}\right)$, m.p. 206-208 ${ }^{\circ} \mathrm{C}$. Its Liebermann-Burchard reaction was positive, with a molecular formula of $\mathrm{C}_{30} \mathrm{H}_{50} \mathrm{O}$ based on ${ }^{13} \mathrm{CNMR}$ and positive HREIMS data at 426.3855 . The IR (KBr) spectra showed the absorptions for hydroxyl group $\left(3423 \mathrm{~cm}^{-1}\right)$ and double bond $\left(1635 \mathrm{~cm}^{-1}\right)$. The ${ }^{13} \mathrm{C}$ NMR spectra revealed 30 carbon signals which were sorted by DEPT experiment as six methyls, thirteen methylenes, five methines, six quaternary carbons, and two olefinic carbons (one $=\mathrm{CH}_{2}$ and one quaternary).

The ${ }^{1} \mathrm{HNMR}$ and ${ }^{13} \mathrm{CNMR}$ spectra of compound 2 showed signals for five tertiary methyls $\left(\delta_{\mathrm{H}} 0.72,0.81,0.95\right.$, $0.95,0.96)$, one vinylic methyl $\left(\delta_{\mathrm{H}} 1.75\right)$, and two protons of an isopropenyl moiety $\left(\delta_{\mathrm{H}} 4.77\right)$. One vinylic methyl at $\delta$ $1.75(3 \mathrm{H}, \mathrm{s}, \mathrm{Me}-30)$, two protons of an isopropenyl moiety at $\delta$ 4.78. These showed closely similar ${ }^{13} \mathrm{CNMR}$ chemical shifts with the reported hopane triterpene [5], except for the side chain carbons, indicating that this compound also possesses a hopane skeleton. The conclusion was confirmed by the HMBC and NOE correlations from compound 2: in the HMBC spectra, the $\mathrm{H}_{2}-29$ showed correlations with the carbon at $\delta 25.0(\mathrm{C}-30)$ and $\delta 46.5$ (C-21). The chemical shift of two protons of terminal alkenes of H-29 at $\delta 4.78$ also supported the hopane skeleton. According to the literature [6], if the skeleton was lupane, the chemical shift of H-29 should be at around 4.57 and 4.69 , so the skeleton was hopane rather than lupane.

Additionally, further signals were observed at the presence of a hydroxymethylene group $\{\delta \mathrm{H}: 3.44(1 \mathrm{H}, \mathrm{d}, J=$ $10.8 \mathrm{~Hz}), 3.73(1 \mathrm{H}, \mathrm{d}, J=10.8 \mathrm{~Hz}) ; \delta \mathrm{C}: 65.5\}$. It was proved by HSQC spectrum that $\delta \mathrm{C} 65.5$ was both connected with $\delta \mathrm{H} 3.44$ and 3.73. While $\delta \mathrm{H} 3.44$ and 3.73 showed longrang connection with $\delta \mathrm{C} 26.8,35.6,38.6$, and 56.8 , it was speculated to be a hydroxyl group linked to C-23 or C-24. The key HMBC correlations were shown in Figure 1. The ${ }^{13} \mathrm{C}$

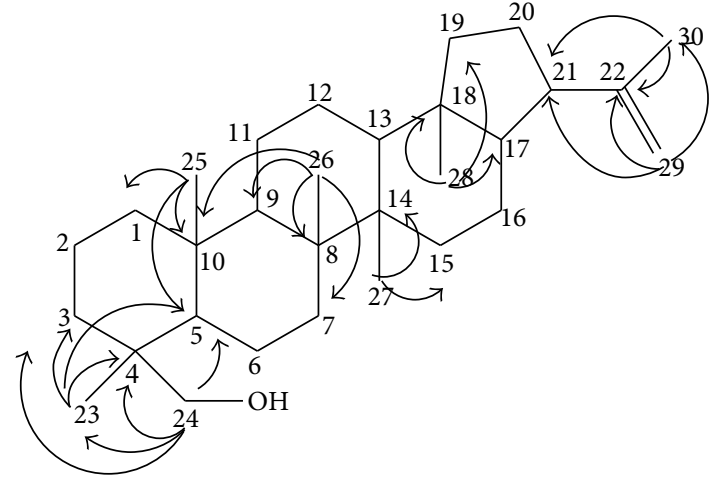

FIGURE 1: Key HMBC correlations of compound 2.

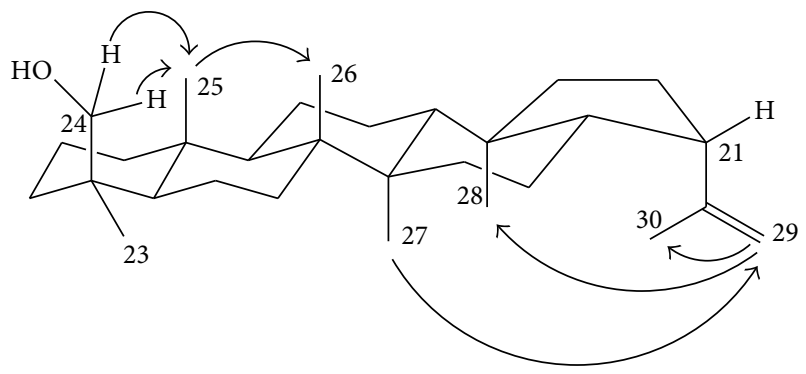

FIgURE 2: The key NOE correlations of compound 2.

and ${ }^{1} \mathrm{H}$ NMR data and key HMBC correlations were shown in Table 1.

In the NOESY spectrum, H-25 showed NOE correlations with $\mathrm{H}-24$ and $\mathrm{H}-26$, but has no NOE correlations with $\mathrm{H}-23$ or H-27. H-29 showed NOE correlations with $\mathrm{H}-27, \mathrm{H}-28$, and $\mathrm{H}-30$. The key NOE correlations were shown in Figure 2. It was reported that when the allyl was linked to C-21 in $\alpha$ orientation, H-29 was a single signal [5]. So C-24, C-25, and $\mathrm{C}-26$ were determined to be in $\beta$-oriented while C-23, C-27, C-28, C-29, and C-30 were determined to be in $\alpha$-oriented. Therefore, the structure of compound 2 was determined to be hopane-22(29)-en-24ol.

According to the literature [7], compounds 1 and 3 were identified as hop-22(29)-ene and adiantone, respectively. By comparison with literature data $[8,9]$, the compounds 4, 5, and 6 were identified as 22-hydroxyhopane, $6 \alpha, 22-$ dihydroxyhopane, and 17(21)-hopene, respectively.

3.2. The Cytotoxicity of Compounds 1-6 in RAW264.7 Cells. We determined the cytotoxicity of the six pentacyclic triterpenes on RAW264.7 cells by MTT assay (Figure 3). Cell viability was not affected 24 hours after the treatment with the six pentacyclic triterpenes at $200 \mu \mathrm{M}$. Therefore, concentrations up to $200 \mu \mathrm{M}$ were selected for subsequent experiments.

Cells were incubated in the presence of the six compounds, respectively. Cell viability was measured by the MTT assay. Data are expressed as the means \pm S.D. of the six different compounds. The six compounds at $200 \mu \mathrm{M}$ were not cytotoxic. 
TABle 1: ${ }^{1} \mathrm{H}(400 \mathrm{MHz})$ and ${ }^{13} \mathrm{C}(100 \mathrm{MHz})$ NMR spectral data for compound 2 in $\mathrm{CDCl}_{3}$.

\begin{tabular}{|c|c|c|c|}
\hline No & ${ }^{1} \mathrm{H}-\mathrm{NMR}$ & ${ }^{13} \mathrm{C}-\mathrm{NMR}$ & $\operatorname{HMBC}(\mathrm{H} \rightarrow \mathrm{C})$ \\
\hline 1 & $0.82(\mathrm{~m}), 1.67(\mathrm{~m})$ & 40.4 & - \\
\hline 2 & $1.38(\mathrm{~m}), 1.51(\mathrm{~m})$ & 18.3 & - \\
\hline 3 & $0.93(\mathrm{~m}), 1.75(\mathrm{~m})$ & 35.6 & - \\
\hline 4 & - & 38.6 & - \\
\hline 5 & $0.87(\mathrm{dd}, J=12.4,1.6)$ & 56.8 & - \\
\hline 6 & $1.30(\mathrm{~m}), 1.59(\mathrm{~m})$ & 18.9 & - \\
\hline 7 & $1.21(\mathrm{~m}), 1.45(\mathrm{~m})$ & 33.6 & - \\
\hline 8 & - & 42.0 & - \\
\hline 9 & $1.26(1 \mathrm{H}, \mathrm{d}, J=12.4)$ & 50.1 & - \\
\hline 10 & - & 37.0 & - \\
\hline 11 & $1.27(\mathrm{~m}), 1.52(\mathrm{~m})$ & 21.1 & - \\
\hline 12 & $1.37(\mathrm{~m}), 1.43(\mathrm{~m})$ & 24.0 & - \\
\hline 13 & $1.35(1 \mathrm{H}, \mathrm{d}, J=2.8)$ & 49.0 & - \\
\hline 14 & - & 41.9 & - \\
\hline 15 & $1.22(\mathrm{~m}), 1.39(\mathrm{~m})$ & 33.7 & - \\
\hline 16 & $1.41(\mathrm{~m}), 1.63(\mathrm{~m})$ & 21.6 & - \\
\hline 17 & $1.39(\mathrm{~m})$ & 54.9 & - \\
\hline 18 & - & 44.8 & - \\
\hline 19 & $\begin{array}{c}1.02(1 \mathrm{H}, \mathrm{d}, J=7.2) \\
1.60(1 \mathrm{H}, \mathrm{dd}, J=7.2,3.2)\end{array}$ & 41.9 & - \\
\hline 20 & $1.82(\mathrm{~m}), 1.85(\mathrm{~m})$ & 27.4 & - \\
\hline 21 & $2.6(1 \mathrm{H}, \mathrm{td}, J=10.4,7.2)$ & 46.5 & - \\
\hline 22 & - & 148.8 & - \\
\hline 23 & $0.96(3 \mathrm{H}, \mathrm{s})$ & 26.8 & $\mathrm{C}_{3}, \mathrm{C}_{4}, \mathrm{C}_{5}, \mathrm{C}_{24}$ \\
\hline 24 & $\begin{array}{l}3.7(1 \mathrm{H}, \mathrm{d}, J=10.8) \\
3.4(1 \mathrm{H}, \mathrm{d}, J=10.8)\end{array}$ & 65.5 & $\mathrm{C}_{3}, \mathrm{C}_{4}, \mathrm{C}_{5}, \mathrm{C}_{23}$ \\
\hline 25 & $0.81(3 \mathrm{H}, \mathrm{s})$ & 16.4 & $\mathrm{C}_{1}, \mathrm{C}_{5}, \mathrm{C}_{9}, \mathrm{C}_{10}$ \\
\hline 26 & $0.95(3 \mathrm{H}, \mathrm{s})$ & 16.6 & $\mathrm{C}_{7}, \mathrm{C}_{8}, \mathrm{C}_{9}, \mathrm{C}_{10}$ \\
\hline 27 & $0.95(3 \mathrm{H}, \mathrm{s})$ & 16.7 & $\mathrm{C}_{14}, \mathrm{C}_{15}$ \\
\hline 28 & $0.72(3 \mathrm{H}, \mathrm{s})$ & 16.1 & $\mathrm{C}_{13}, \mathrm{C}_{17}, \mathrm{C}_{18}, \mathrm{C}_{19}$ \\
\hline 29 & $4.77(2 \mathrm{H}, \mathrm{s})$ & 110.3 & $\mathrm{C}_{21}, \mathrm{C}_{22}, \mathrm{C}_{30}$ \\
\hline 30 & $1.75(3 \mathrm{H}, \mathrm{s})$ & 25.0 & $\mathrm{C}_{21}, \mathrm{C}_{22}, \mathrm{C}_{29}$ \\
\hline
\end{tabular}

3.3. Assay for Inhibitory Activities against NO Production. The potent anti-inflammation of some triterpenes had received considerable attention, such as triterpene alcohols from the flowers of compositae [10]. Therefore, it was meaningful to investigate the anti-inflammatory effects of these pentacyclic triterpene isolated from $H$. tyermanni. In this study, compounds 1-6 were tested for inhibitory activities against LPSinduced NO production to RAW264.7 at a concentration range from $12.5 \mu \mathrm{M}$ to $200 \mu \mathrm{M}$ (Figure 4). The $\mathrm{IC}_{50}$ values were in the range of $50-100 \mu \mathrm{M}$ except for compounds 1 and 6, which were attributed to the absence of the hydroxyl group. Four compounds (compounds 2, 3, 4, and 5) with oxygen as hydroxyl or carbonyl groups exhibited good inhibitory activities against LPS-induced NO production in RAW264.7 macrophages. Interestingly, the compound 2 with a $24-\mathrm{OH}$ exhibited better inhibitory activity than the compound $\mathbf{1}$ without a hydroxyl. So, it was inferred that the $24-\mathrm{OH}$ may play an important role in inhibiting NO production in RAW264.7 macrophages. Although there were not enough pentacyclic triterpenes to discuss the structure-activity relationship, our data offered a reference that pentacyclic triterpenes were an important source of new anti-inflammatory agents.

\section{Conclusion}

In conclusion, One new pentacyclic triterpene from $H$. tyermanni, hopane-22(29)-en-24ol, was isolated and elucidated on the basis of $1 \mathrm{D}$ and 2D NMR spectral techniques. In addition, it exhibited stronger inhibitory activity than that of 


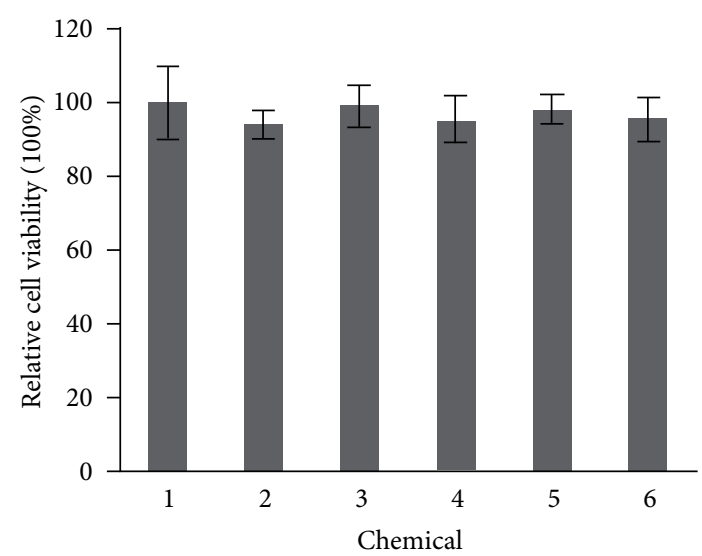

FIgURe 3: Cytotoxicity of compounds 1-6 in RAW264.7 cells.

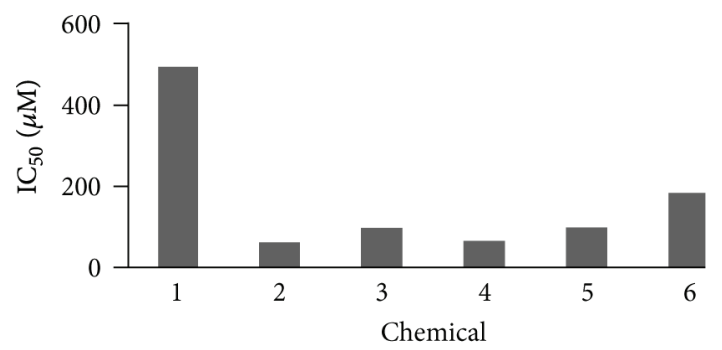

FIGURE 4: Inhibitory effects of the six pentacyclic triterpene compounds 1-6 isolated from $H$. tyermanni Moore LPS-induced NO production in RAW264.7 macrophages $(n=4)$. The NO level was assayed by Griess reagent.

the other five known compounds against LPS-induced NO production in RAW264.7 macrophages.

\section{Acknowledgments}

This work was supported by the National Natural Science Foundation of China (no. 20772047, 21310104) and the Natural Science Foundation of Guangdong Province (no. 32210018).

\section{References}

[1] Q. M. Hu, Flora Reipublicae Popularis Sinicae, vol. 2, Science Press, Beijing, China, 2006.

[2] X. Y. Qin, J. Y. Luo, and Z. G. Gao, Chinese Yao Medicines Pharmacy, National Press, 2002.

[3] J. J. Qin, H. Z. Jin, J. X. Zhu et al., "New sesquiterpenes from Inula japonica Thunb. with their inhibitory activities against LPS-induced NO production in RAW264.7 macrophages," Tetrahedron, vol. 66, no. 48, pp. 9379-9388, 2010.

[4] M. Jin, S. J. Suh, J. H. Yang et al., "Anti-inflammatory activity of bark of Dioscorea batatas DECNE through the inhibition of iNOS and COX-2 expressions in RAW264.7 cells via NF- $\kappa$ B and ERK1/2 inactivation," Food and Chemical Toxicology, vol. 48, no. 11, pp. 3073-3079, 2010.

[5] H. Ageta, K. Shiojima, H. Suzuki, and S. Nakamura, "NMR spectra of triterpenoids. I. Conformation of the side chain of hopane and isohopane, and their derivatives," Chemical and Pharmaceutical Bulletin, vol. 41, no. 11, pp. 1939-1943, 1993.

[6] P. M. Mishra, A. Sree, B. Dash, M. Panigrahi, and S. K. Padhan, "Isolation of a deoxy lupane triterpene carboxylic acid from Finlaysonia obovata (a mangrove plant)," Fitoterapia, vol. 81, no. 8, pp. 977-981, 2010.

[7] F. Wang, C. Y. Chi, C. H. He, J. C. Shao, and Y. Z. Cen, "Chemical constituents from Humata tyermanni Moore," Chinese Traditional Patent Medicine, vol. 33, p. 645, 2011.

[8] M. Neves, R. Morais, S. Gafner, and K. Hostetimann, “Three triterpenoids and one flavonoid from the liverwort Asterella blumeana grown in vitro," Phytotherapy Research, vol. 12, no. S1, pp. S21-S24, 1998.

[9] H. Ageta, K. Shiojima, Y. Arai, H. Suzuki, and T. Kiyotani, "NMR spectra of triterpenoids. II. Hopenes and migrated hopenes," Chemical and Pharmaceutical Bulletin, vol. 42, no. 1, pp. 39-44, 1994.

[10] T. Akihisa, K. Yasukawa, H. Oinuma et al., "Triterpene alcohols from the flowers of compositae and their anti- inflammatory effects," Phytochemistry, vol. 43, no. 6, pp. 1255-1260, 1996. 

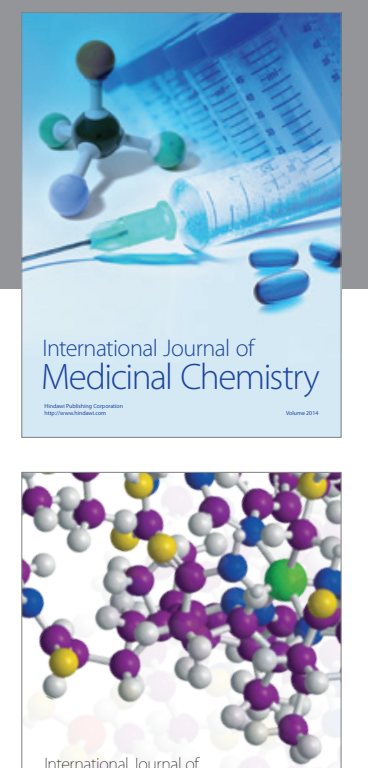

\section{Carbohydrate} Chemistry

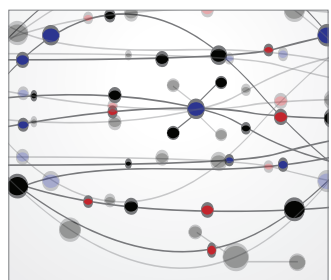

The Scientific World Journal
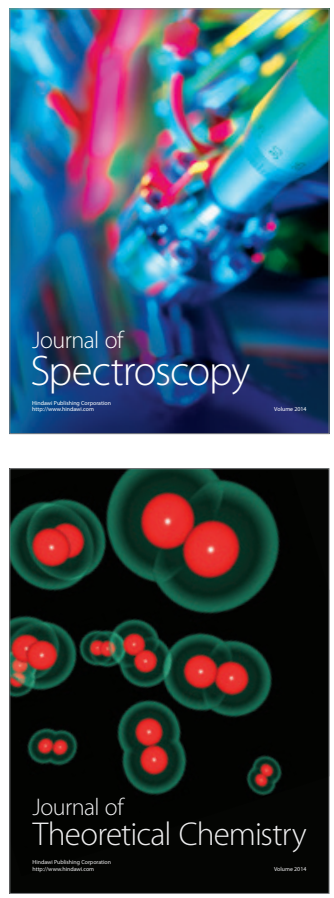
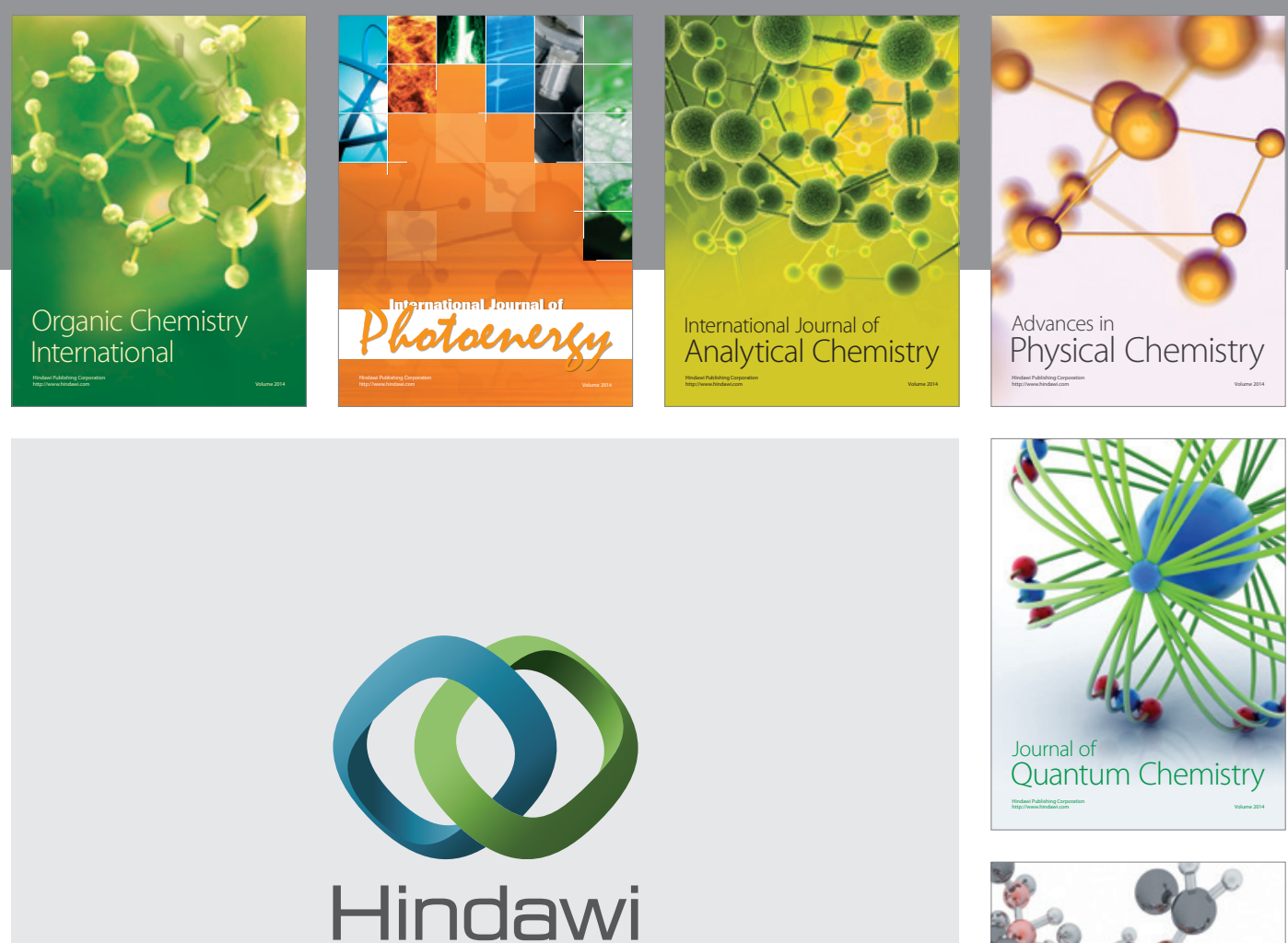

Submit your manuscripts at

http://www.hindawi.com

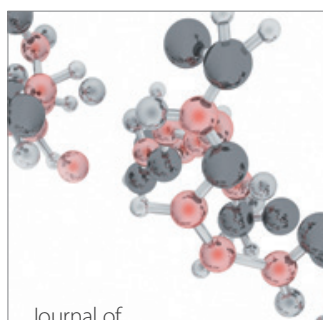

Analytical Methods

in Chemistry

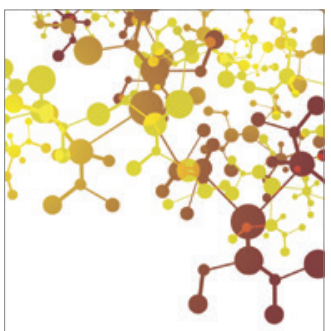

Journal of

Applied Chemistry

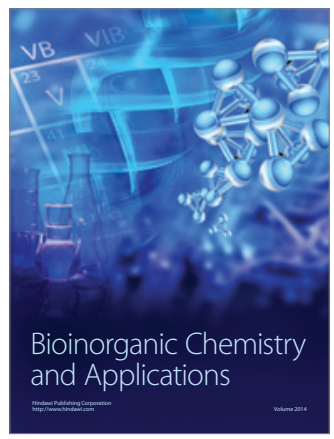

Inorganic Chemistry
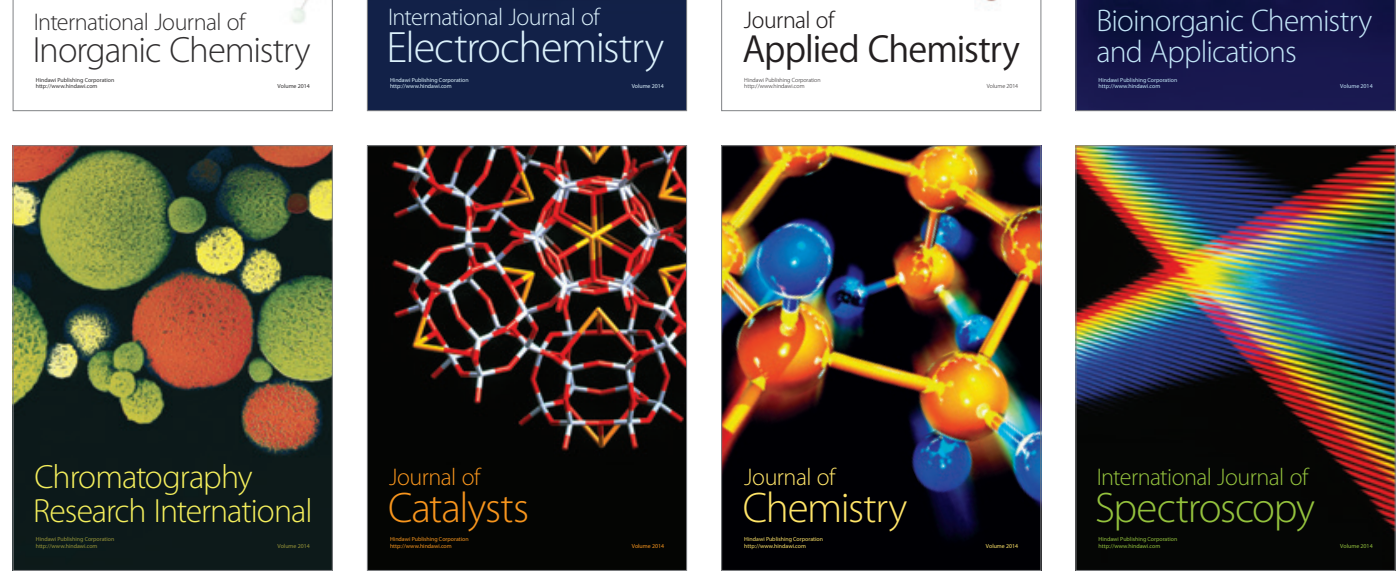